\section{Commentary: Is perfusate arterial oxygen tension the best barometer of inflammation following cardiopulmonary bypass for congenital heart surgery?}

\author{
Sergio A. Carrillo, MD, FACS
}

Exposure to cardiopulmonary bypass, with its attendant activation of the inflammatory and coagulation cascade, is inevitable for a patient undergoing congenital heart surgery. Optimal perfusion requires management of physiologic variables such as mean arterial blood pressure, hematocrit level, flow rate, temperature, oxygen delivery $\left(\mathrm{DO}_{2}\right), \mathrm{pH}$, and arterial carbon dioxide tension/arterial oxygen tension $\left(\mathrm{PaO}_{2}\right)$ management. ${ }^{1}$ The ultimate goal is to deliver a healthy, long-term survivor without gross organ dysfunction.

One of the components of $\mathrm{DO}_{2}$ is $\mathrm{PaO}_{2}$. During cardiopulmonary bypass, $\mathrm{PaO}_{2}$ is measured as the oxygen tension in the perfusate $\left(\mathrm{PpaO}_{2}\right)$. In this issue of the Journal, Liu and associates ${ }^{2}$ have conducted an elegant study of the effects of $\mathrm{PpaO}_{2}$ on children ( $>1$ month) and young adults ( $<18$ years) from different geographic locations (and thusly, altitude) across China. The cohort was separated into 2 groups based on the patients' low- or highaltitude residence. The primary outcome, occurrence of severe systemic inflammatory response syndrome (SIRS), was nearly identical (18.27\% vs $18.79 \%$ for low- vs high-altitude, respectively). However, upon a detailed look at the secondary outcomes, patients at greater altitudes had longer hospital length of stay and in-hospital mortality (despite the fact that overall

\footnotetext{
From Nationwide Children's Hospital and The Ohio State University, Columbus, Ohio.

Disclosures: The author reported no conflicts of interest.

The Journal policy requires editors and reviewers to disclose conflicts of interest and to decline handling or reviewing manuscripts for which they may have a conflict of interest. The editors and reviewers of this article have no conflicts of interest.

Received for publication June 24, 2020; revisions received June 24, 2020; accepted for publication June 24, 2020; available ahead of print July 13, 2020.

Address for reprints: Sergio A. Carrillo, MD, FACS, The Heart Center at Nationwide Children's Hospital, 700 Children's Dr, Columbus, OH 43205 (E-mail: sergio. carrillo@nationwidechildrens.org).

J Thorac Cardiovasc Surg 2021;161:2193-4

$0022-5223 / \$ 36.00$

Copyright (c) 2020 by The American Association for Thoracic Surgery

https://doi.org/10.1016/j.jtcvs.2020.06.106
}

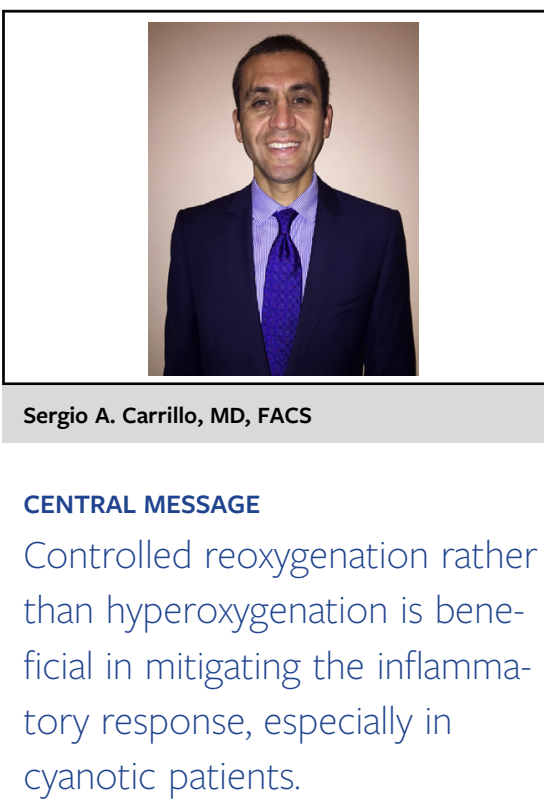

mortality in this cohort of $>6300$ patients was a remarkable $0.35 \%$ ).

With steady ascent in altitude, a multitude of physiologic changes occur, chief among those are enhanced oxygen delivery and uptake, allowing the process of adaptation, or acclimatization. Acclimatization was not accounted for, and it is unknown whether these patients had their surgery performed at a center with an altitude different from where they reside. Furthermore, these adaptive changes start to occur at or above altitudes of $>1500 \mathrm{~m}$ above sea level. ${ }^{3}$ It is difficult to conceive that said adaptations have occurred at the authors' chosen altitude threshold of $500 \mathrm{~m}$. Moreover, this lower threshold may introduce an "altitude bias" that precludes correctly interpreting their results, especially when others ${ }^{4}$ have found equal surgical outcomes at greater altitudes when compared with outcomes at sea level. Lastly, without the preoperative oxygen saturation levels, the gradual oxygen saturation decline seen with decrease in barometric pressure with greater altitudes ${ }^{5}$ could not be analyzed.

The range of $\mathrm{PpaO}_{2}$, to which patients of both groups were exposed, was 250 to $350 \mathrm{~mm} \mathrm{Hg}$, a number that other investigators, ${ }^{6}$ including previous work from the same group, ${ }^{7}$ would define as hyperoxia. Ultimately, using complex statistics, the authors found that a $\mathrm{PpaO}_{2}$ threshold of $>310 \mathrm{~mm} \mathrm{Hg}$ for low-altitude patients and $>350 \mathrm{~mm} \mathrm{Hg}$ for high-altitude patients was associated with a high probability of development of severe SIRS. Based on these findings, the authors recommend keeping $\mathrm{PpaO}_{2}<365 \mathrm{~mm} \mathrm{Hg}$ for all patients. 
Hyperoxia is injurious to the homeostasis of patients with cyanosis and by no means inconsequential. Specific perfusion details, such as flow rate goal or transfusion triggers that impact $\mathrm{DO}_{2}$, were not described. Although not studied by Liu and associates, ${ }^{2}$ other investigators have showed the effects of hyperoxia in the inflammatory response leading to SIRS, in particular: (1) complement activation, interleukin (IL)-6, IL-8, IL-10, or cortisol levels representing whole body inflammation ${ }^{8}$; (2) release of troponin-I reflecting myocardial cell damage and oxidative stress $^{9}$; (3) protein S-100 (cerebral damage); and (4) alpha-glutathione S-transferase (hepatic cell damage). The release of these key markers has been shown to be mitigated by controlled reoxygenation rather than hyperoxygenation, with maximum clinical benefit for univentricular hearts. ${ }^{9}$ By that rationale, controlled reoxygenation rather than hyperoxygenation makes physiologic sense, particularly for single-ventricle (who are in a constant-state of hypoxemia) and cyanotic biventricular patients (whom hypoxemia tends to fluctuate).

In summary, the impact of inflammation in patients undergoing congenital heart surgery can't be underestimated. $\mathrm{PpaO}_{2}$ plays a small, albeit important role, especially when controlled reoxygenation is selectively used for cyanotic and single-ventricle patients.

\section{References}

1. Murphy GS, Hessel EA II, Groom RC. Optimal perfusion during cardiopulmonary bypass: an evidence-based approach. Anesth Analg. 2009;108:1394-417.

2. Liu H, Hu Y, Zheng S, Chen T, Zeng Z, Wu DD, et al; Tedal CH Cardiovascular Discovery Group. Effects of perfusate oxygenation on inflammatory response in congenital heart disease children from low versus high altitude. J Thorac Cardiovasc Surg. 2021;161:2180-90.

3. Paralikar SJ, Paralikar JH. High-altitude medicine. Indian J Occup Environ Med. 2010; 14:6-12.

4. Zhou Z, Malhotra SP, Yu X, Rutledge J, Rebeyka IM, Ross DB, et al. Moderate altitude is not associated with adverse postoperative outcomes for patients undergoing bidirectional cavopulmonary anastomosis and Fontan operation: a comparative study among Denver, Edmonton and Toronto. J Thorac Cardiovasc Surg. 2013;146:1165-71.

5. Rojas-Camayo J, Mejia CR, Callacondo D, Dawson JA, Posso M, Galvan CA, et al. Reference values for oxygen saturation from sea level to the highest human habitation in the Andes in acclimatized persons. Thorax. 2018;73:776-8.

6. Caputo M, Mokhtari A, Rogers CA, Panayiotou N, Chen Q, Ghorbel MT, et al. The effects of normoxic versus hyperoxic cardiopulmonary bypass on oxidative stress and inflammatory response in cyanotic pediatric patients undergoing open cardiac surgery: a randomized controlled trial. J Thorac Cardiovasc Surg. 2009;138: 206-14.

7. Liu H, Zheng SQ, Qian SC, He HH, Xue JR. Haematocrit differences modify the association of cardiopulmonary bypass reoxygenation with acute kidney injury after paediatric tetralogy of Fallot repair. Perfusion. 2020;35:284-9.

8. Madhok AB, Ojamaa K, Haridas V, Parnell VA, Pahwa S, Chowdhury D. Cytokine response in children undergoing surgery for congenital heart disease. Pediatr Cardiol. 2006;27:408-13.

9. Caputo M, Mokhtari A, Miceli A, Ghorbel MT, Angelini GD, Parry AJ, et al. Controlled reoxygenation during cardiopulmonary bypass decreases markers of organ damage, inflammation, and oxidative stress in single-ventricle patients undergoing pediatric heart surgery. J Thorac Cardiovasc Surg. 2014;148:792-801. 